\title{
Arazi hazırlı̆ğ ve kültür bakım yöntemlerinin dar yapraklı dişbudağın (Fraxinus angustifolia ssp. oxcycarpa Vahl.) ağaçlandırma başarısına etkileri
}

Effects of site preparation and post planting cultural treatments on field performance of narrow-leaved ash (Fraxinus angustifolia ssp. oxycarpa Vahl.) plantings

Cemal FIDAN ${ }^{1}$

Alikemal ÖZBAYRAM ${ }^{2}$

H. Cemal GÜLTEKİN ${ }^{3}$

Hülya TAMYÜKSEL ${ }^{3}$

Necat DEMIRSU

Erol CABAK ${ }^{1}$

\author{
' Kavak ve Hızlı Gelişen Orman Ağaçları \\ Araştırma Enstitüsü Müdürlüğü, İZMİT \\ ${ }^{2}$ Düzce Üniversitesi Orman Fakültesi, \\ DÜZCE \\ ${ }^{3}$ Emekli, İZMİT
}

\begin{abstract}
Sorumlu yazar (Corresponding author) Cemal FIDAN

cemalfidan@ogm.gov.tr
\end{abstract}

Geliş tarihi (Received)

07.01.2019

Kabul Tarihi (Accepted)

27.03.2019

Atıf (To cite this article): FIDAN, C, ÖZBAYRAM, A , GÜLTEKIN, H , TAMYÜKSEL, H , DEMIRSU, N , CABAK, E . (2019). Arazi Hazır$\operatorname{llğ}_{1}$ ve Kültür Bakım Yöntemlerinin Dar Yaprakl Dişbudağın (Fraxinus angustifolia ssp. oxcycarpa Vahl.) Ağaçlandırma Bașarısına Etkileri. Ormanc1lık Araştırma Dergisi, 6 (2), 119-127. DOI: https://doi.org/10.17568/ogmoad.509356

Creative Commons Atıf Türetilemez 4.0 Uluslararas Lisansı ile lisanslanmışıtır.

\section{$\ddot{O} z$}

$\mathrm{Bu}$ çalışma, dar yapraklı dişbudak (DYD) plantasyon sahalarında, farklı arazi hazırlığı ve kültür bakım işlemlerinin, DYD fidanlarının yaşama yüzdesi ve üç yıllık büyümesine etkilerini belirlemek için yapılmıştır. Bölünmüş parseller deneme desenine göre planlanan çalışmada arazi hazırlığı (geleneksel ve herbisit uygulama) ve kültür bakımı (kontrol, bir yıl çapa ile ot alma, iki yıl çapa ile ot alma, bir y1l kontak herbisit ve iki y1l kontak herbisit) faktörleri işlem olarak alınmıştır. Varyans analizi sonuçlarına göre geleneksel arazi hazırlığı ve herbisit uygulama işlemlerinin arasında anlamlı fark çıkmamıştır. Kültür bakım işlemleri, fidan yaşama yüzdesi ve boy/çap (B/Ç) oranına istatistiki anlamda bir etki yapmamıştır, ancak fidanların dip çap artımı, boy ve hacim artımına etkisi anlamlıdır. Fidanların dip çapı ve boy gelişimi tüm kültür işlemlerinde benzer ve kontrolden sırasıyla $\% 56$ ve $\% 43$ daha fazladır. Fidan hacmi iki yıl çapa ile ot alma hariç kültür işlemlerinde benzer ve kontrolden $\% 53$ daha yüksek bulunmuştur. Sonuç olarak fidan gelişimi açısından arazi hazırlığı yönüyle önemli bir fark çıkmamıştır, ancak dikimde boylu fidan kullanılmasına rağmen, kültür bakımlarının fidan gelişiminde etkili olduğu ve mutlak surette yapılması gerektiği söylenebilir. Pratik ve daha az maliyetli olması nedeniyle, geleneksel arazi hazırlığ 1 ve çapa gibi kültür bakımları yerine herbisit kullanımı tercih edilebilir.

Anahtar kelimeler: Taban arazi, dişbudak ormanı, arazi hazırlı̆̆ı, kültür bakımı

\begin{abstract}
This study was conducted to determine the effects of different site preparation and weed control treatments on three-year seedlings' growth performance and survival ratios of narrow leaved ash plantation sites. Two different site preparations (conventional and systemic herbicide application) and five different weed control treatments (the control, one-year land clearing, two-year land clearing, one-year herbicide and two-year herbicide) were tested in a split-plot experimental design. According to the ANOVA, site-preparation treatments did not have a significant effect on any dependent variable of seedlings. Except the control treatment, height and diameter increments of seedlings were similar. Height and diameter increments were found $56 \%$ and $43 \%$ higher in weed control treatments, respectively, than that in the control. Except for the two-year land clearing treatment, volume of seedlings were similar, with a 53\% higher than that in the control. As a result, there were no significant effects on seedling growth for site preparation treatments. However, significant differences were found for weed control treatments. It has shown that weed control shall be carried out although tall seedlings are used for planting. Herbicide usage can be preferred instead of conventional site preparation and weed control methods since it is more economical and more practical.
\end{abstract}

Keywords: Bottomland, ash forest, site preparation, tending 


\section{Giriş}

Sivri meyveli dişbudak olarak da isimlendirilmiş olan dar yapraklı dişbudak (Fraxinus angustifolia Vahl.), çoğunlukla kuzey yarım kürenin ılıman ve ender olarak sub-tropik ve tropik bölgelerinde yayılış göstermektedir. Türkiye'de dişbudağın üç türü, adi dişbudak (Fraxinus excelsior L.), çiçekli dişbudak (Fraxinus ornus L.), dar yapraklı dişbudak (Fraxinus angustifolia Vahl.) ve bu türlere ait 7 alt tür bulunmaktadır (Yaltırık, 1978). Diğer taraftan hızlı gelişmesi yanında çok değerli odun özellikleri nedeniyle önemli bir yere sahip olduğu belirtilmektedir (Çiçek ve Yılmaz, 2002; Fraxigen, 2005). Bu tür ülkemizde en yaygın bulunan dişbudak türü olup Karadeniz ve Marmara bölgesindeki taban arazi ormanlarının hâkim ağaç türüdür. Bununla birlikte ülkemizin tüm coğrafi bölgelerinde yayılış gösterebilen nadir ağaç türlerinden biridir (Yaltırık, 1978; Davis, 1987; Mayer ve Aksoy, 1998).

Türün taban arazilerdeki orman alanları, yetişme ortamı koşulları nedeniyle (zayıf drenaj, ağır killi toprak vb.) bitki yetişmesi bakımından marjinal (yüksek taban suyu, 1slaklık ve ağır killi topraklar vb.) nitelikte kabul edilmektedir (Pliura 1999). Diğer yandan, bu sahalarda yetişme ortamı koşulları nedeniyle yoğun ve boylu diri örtü (1,5-2,0 m) rekabeti söz konusudur (Çiçek ve ark., 2007b). Türkiye'de, taban arazideki DYD hâkimiyetindeki doğal ormanlar geçmişte büyük tahrip gördüğü için hemen hemen tamamı son 50-60 yılda saf DYD plantasyonlarına dönüştürülmüştür. Dönüştürme olayı, türün ülkemizde en geniş ormanlarını kurduğu Adapazarı yöresinde yoğunlaşmıştır (Çiçek, 2004).

Adapazarı yöresindeki taban arazilerde 50 yıl önce kurulan DYD plantasyonları idare süresini doldurmuştur. $\mathrm{Bu}$ sahalar son yıllarda tıraşlanarak tekrar dikimle DYD plantasyonu olarak kurulmaktadır. Orman Genel Müdürlüğü dişbudak orman alanlarında endüstriyel plantasyon işletmeciliği yapılmasını ve bu hususta Sakarya Orman Bölge Müdürlüğü sınırları içerisinde yer alan dişbudak sahalarında pilot uygulama başlatılmasını karara bağlamıştır. Ağaçlandırmaların ilk yıllarında yapılan arazi hazırlı̆̆ giderleri içerisinde en büyük paya sahiptir (Birler, 2010). Yeni kesilmiş DYD plantasyonlarının yeniden DYD ağaçlandırmaları tesis edilmek istenmesi durumunda arazide bulunan kök kütükleri ve kökler toprak işlemeye engel teşkil etmekte, bunların sökülmesi durumunda ise maliyeti yüksek tutmaktadır. Bu çalışmada esas itibariyle, tıraşlama kesim yapılan DYD plantasyon alanlarında, dikim öncesi arazi hazırlığı ve dikim sonrası kültür ba- kım çalışmalarında yeni yöntemlerin dikim başarısını artırması ve maliyeti düşürmesi konuları ele alınmıştır. Arazi hazırlığında hâlihazırdaki uygulamayla sahada bulunan ağaç kökleri ekskavatör ile sökülmekte ve çıkarılan kökler dozerle şeritler hâlinde yığılmaktadır. Bu esnada organik madde ve bitki besin maddelerince zengin olan verimli üst toprağın önemli bir kısmı yığınlara gitmekte ve bunun fidan gelişimlerini olumsuz yönde etkilediği düşünülmektedir. Dikim öncesi arazi hazırlığ1 kapsamında, sahada bulunan odunsu diri örtünün (kütük sürgünleri ve sahada bulunan diğer odunsu diri örtü) herbisit kullanılarak bertaraf edilmesi mevcut uygulamaya alternatif olarak ele alınmış ve incelenmiştir. Yine bu çalışmayla, dikim sonrası kültür bakım uygulamaları kapsamında, fidan etrafında ot alma ve çapa işlemi ile herbisit kullanımının diri örtüyü bertaraf etme ve fidanların gelişimlerine olan etkileri incelenmiştir.

\section{Materyal ve Yöntem}

\subsection{Deneme sahasının tanıtımı}

Deneme alan1; Sakarya Orman Bölge Müdürlüğü, Hendek Orman İşletme Müdürlüğü, Süleymaniye Orman İşletme Şefliği orman alanında, Soğuksu köyü mülki hudutları içerisinde ve Mudurnu çayı kenarında tıraşlama kesim yapılan dişbudak ve akçaağaç türlerinden oluşan karışık meşcerede kurulmuştur. Yükselti 20-25 m arasında değişmekte olup eğim \%0-2 dolayındadır. Deneme alanının denizden uzaklığı $28 \mathrm{~km}$, coğrafik konumu ise $40^{\circ} 51^{\prime} 41.86^{\prime \prime}-40^{\circ} 51^{\prime} 50.73$ ' kuzey enlemleri ile $30^{\circ} 35^{\prime} 24.69$ '-30³5'37.51" doğu boylamları arasında yer almaktadır. Toprak yapısı esas itibariyle Mudurnu ve Dinsiz Çayları ile Sakarya nehrinin taşıdığ1 tortullardan oluştuğu için alüvyal karakterdedir. Saha yüksek kil içeriğine sahip olup kil oranı derinlikle birlikte artmaktadır. Aktüel toprak asitliği (pH) 6,00-8,09 arasında değişim göstermekte olup çoğunlukla 7,0'den yüksektir. Organik karbon miktarı alt horizonlara doğru azalmakta olup Ah horizonunda \%8 civarındadır. Toprakların kireç içeriği yüksektir (Çiçek ve Yılmaz, 2002).

\subsection{Yöntem}

Çalışma, arazi hazırlığı (iki seviyeli) ve kültür bakımı (beş seviyeli) faktörleri bölünmüş parseller deneme desenine göre planlanmıştır. Arazi hazırlığ1, geleneksel arazi hazırlığ 1 işlemi ile herbisit uygulama işleminden oluşmaktadır. Geleneksel arazi hazırlığı tıraşlama kesim sonrası ekskavatörle sökülen köklerin dozer tarağı ile temizlenerek 45-50 m arayla yığılmasının ardından yığınlar aras1 sahanın dozere arkadan monteli 2'li riperle alt toprak işlemesi yapılarak uygulanmıştır. Arazi ha- 
Zırlığında herbisit uygulama işlemi ise kök sökümü ve herhangi bir toprak işlemesi yapmadan, kesilen ağaç kütüklerinden çıkan sürgünler ile sahada bulunan diğer odunsu bitkilerden çıkan sürgünlere, ekim ayının başında, Glyphosate etken maddeli ve Stanby ticari isimli sistemik herbisit $1 / 15$ oranında suyla seyreltilerek uygulanmıştır.

Kültür bakımı kapsamında fidan etrafında çapa ile ot alma ve herbisit kullanımının etkileri 5 seviyede incelenmiştir. Bunlar; kültür bakımı uygulanmayan-kontrol (B0), bir yıl ot alma ve çapalama (B1), iki yıl ot alma ve çapalama (B2), bir yıl herbisit (paraquat) uygulama (B3) ve iki yıl herbisit uygulama (B4) şeklindedir. Ot alma ve çapa işlemi yılda bir defa olmak üzere haziran ayının başında, herbisit ise yılda iki defa uygulanmıştır. İlk herbisit uygulama işlemi nisan ayında, ikincisi ise temmuz ayında yapılmıştır. İlkbahar döneminde saha sular altında kaldığı için dikim sonbaharda yapılmıştır.

Sahada dikim çukurları iş gücü kullanılarak $40 \mathrm{~cm}$ genişlik ve $30 \mathrm{~cm}$ derinliğinde açılmıştır. Dikim işlemi, 2012 yılı sonunda (aralık ayı) çıplak köklü, $1+0$ yaşlı ve $70 \mathrm{~cm}$ 'den daha boylu DYD fidanları kullanılarak ve 2,0x2,0 m aralık mesafe esas alınarak yapılmıştır. Her işlem parselinde yanlardaki tecrit, ortadaki ölçüm olmak üzere 3 sıra hâlinde toplam 75 adet fidan dikimi gerçekleştirilmiştir.

Her yıl vejetasyon mevsimi sonunda işlem parsellerinde orta sırada bulunan 25 adet fidanın çap ve boyları ölçülmüştür. Dip çap ölçümü fidanların yerden yaklaşık 2-3 cm yükseklikteki noktasından ve milimetre hassasiyetindeki kumpasla, fidan boyu ölçümü ise $\mathrm{cm}$ hassasiyetindeki boy ölçerler kullanılarak yerden tepeye kadar olan tüm boyu ölçülerek yapılmıştır. Boy-dip çap (B/Ç) oranı hem 2012 y1lı hem de 2015 yılı için fidanların boyunun dip çapa oranı $(\mathrm{cm} / \mathrm{cm})$ ile hesaplanmıştır. Fidan hacmi ise bireylerin paraboloit biçimli oldukları kabul edilmiş ve fidan hacimleri denklem (1) ile hesaplanmıştır (Kalıpsız 1984).

$$
v=\left(\frac{1}{r+1}\right)\left(\frac{\pi}{4} d_{0}{ }^{2} h\right)
$$

Fidanların 3 yıllık çap, boy ve hacim artımları; 2015 yılı değerlerinden 2012 yılı değerlerin fark1 alınarak elde edilmiştir.

\section{3. İstatistiki analiz}

Arazi hazırlığı ve farklı kültür bakım işlemlerinin, fidan yaşama yüzdesi, dip çap artımına, fidan boy büyümesine, hacim artımlarına ve B/Ç oranına etkilerini görmek maksadıyla, elde edilen veriler iki yönlü varyans analizine tabi tutulmuştur. Gruplar arasında ortalamaların farklılığını görmek için ise Duncan testi uygulanmıştır. Analiz yapmadan önce verilerin normal dağılımı ve homojen dağılım gösterip göstermediği kontrol edilmiştir. İstatistiki analizler TARIST paket programı yardımıyla gerçekleştirilmiştir.

Tablo 1. DYD fidanlarının dikim sonrası 2012 ve 2015 yıllarındaki dip çapları (cm) Table 1. Seedling diameters (cm) of narrow leaved ash in 2012 and 2015

\begin{tabular}{ccccccccccc}
\hline \multirow{2}{*}{$\begin{array}{c}\text { Ölçüm } \\
\text { zaman1 }\end{array}$} & \multicolumn{4}{c}{ Arazi hazırlığında herbisit uygulama } & \multicolumn{5}{c}{ Geleneksel arazi hazırlı̆̆ 1} \\
\cline { 2 - 10 } & B0 & B1 & B2 & B3 & B4 & B0 & B1 & B2 & B3 & B4 \\
\hline 2012 y111 & 0,97 & 1,06 & 1,03 & 1,13 & 1,09 & 0,78 & 0,91 & 0,86 & 0,93 & 0,85 \\
2015 y1l1 & 1,64 & 1,95 & 1,87 & 2,06 & 2,10 & 1,34 & 1,86 & 1,89 & 1,91 & 1,96 \\
\hline
\end{tabular}

Tablo 2. Arazi hazırlığı ve kültür bakım işlemlerinin fidan dip çap artımına ilişkin varyans analizi sonuçları (AH: Arazi hazırlığı, KB: Kültür bakımı)

Table 2. ANOVA results on the effects of site preparation and weed control treatments on the diameter increment (AH: site preparation, KB: tending)

\begin{tabular}{lccccc}
\hline Varyasyon kaynağı & $\begin{array}{c}\text { Serbestlik } \\
\text { derecesi }\end{array}$ & $\begin{array}{c}\text { Kareler } \\
\text { toplamı }\end{array}$ & $\begin{array}{c}\text { Kareler } \\
\text { ortalamas }\end{array}$ & Hesaplanan F & $\begin{array}{c}\text { Alfa tipi } \\
\text { hata ihtimali }\end{array}$ \\
\hline Arazi hazırlığ1 & 1 & 0,25 & 0,025 & $0,100 \mathrm{~ns}$ & 0,7589 \\
Hata-1 & 4 & 0,990 & 0,248 & & \\
Kültür bakımı & 4 & 0,651 & 0,163 & $3,402^{*}$ & 0,0337 \\
AH*KB & 4 & 0,066 & 0,017 & $0,346 \mathrm{~ns}$ & 0,8435 \\
Hata-2 & 16 & 0,766 & 0,048 & & \\
Genel & 29 & 2,498 & 0,086 & & \\
\hline
\end{tabular}

ns $=$ önemsiz (not significant) $*=$ önemli $\% 5$ alfa seviyesinde (significant at alfa level $\% 5$ ), ** = önemli $\% 1$ alfa seviyesinde (significant at alfa level \%1) 


\section{Bulgular}

\subsection{Fidan Yaşama Yüzdesi}

Arazi hazırlığı ve kültür bakım işlemleri ile etkile- şimlerinin fidan yaşama yüzdelerine etkisi önemsiz bulunmuştur ( $\mathrm{P}>0,05$; Şekil 1). Grafikten de anlaşılacağı üzere tüm işlem parsellerinde yaşama yüzdesi $\% 80$ ve üzerindedir.

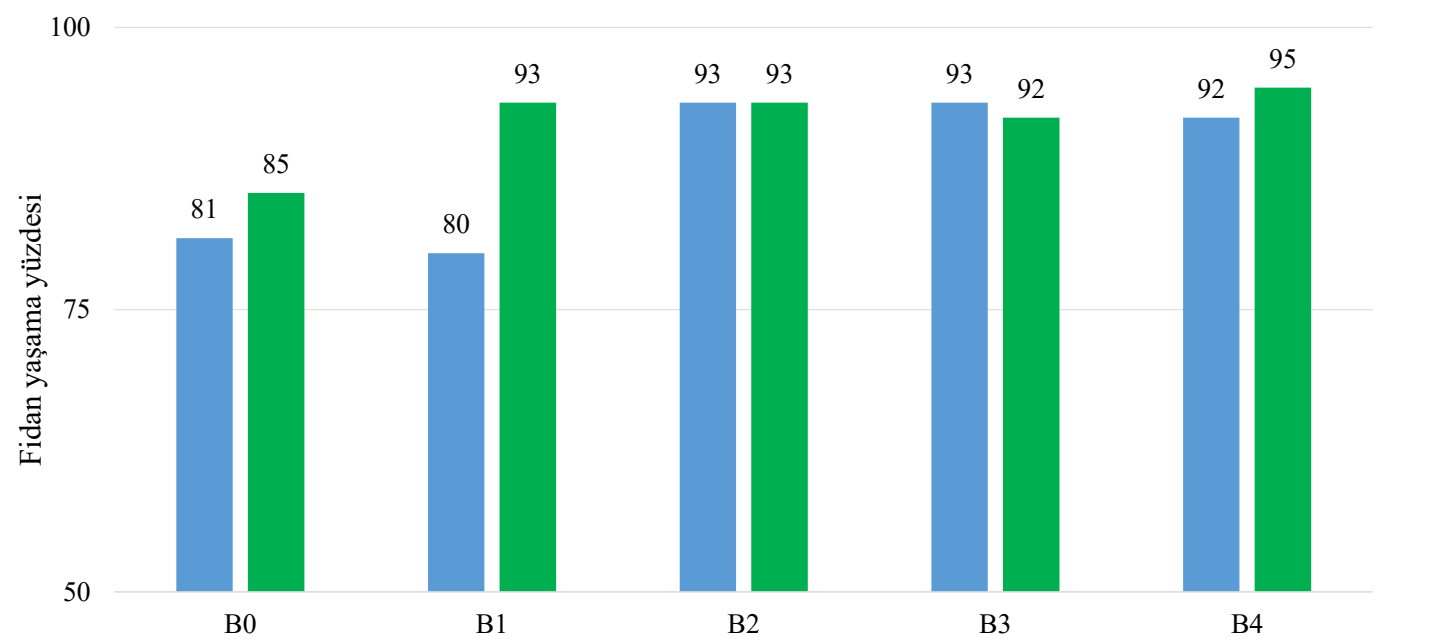

$\mathrm{BO}=$ kontrol, B1=bir y1l çapa, B2=iki yıl çapa, B3=bir y1l herbisit, B4=iki y1l herbisit

घeleneksel arazi hazırlığı $\quad$ Arazi hazırlı̆̆ında herbisit uygulama

Şekil 1. Arazi hazırlığı ve kültür bakım işlemlerinin fidan yaşama yüzdesine etkileri

Figure 1. Effect of site preparation and weed control treatments on survival ratios of seedlings

\subsection{Dip çap}

Dikim sonrası 2012 yılı ve 2015 yılı dip çap değerleri Tablo 1'de verilmiştir. Fidanların 2012 yılı ortalama dip çapı $0,96 \mathrm{~cm}$ iken bu değer 2015 yılında 1,86 cm’ye çıkmıştır. Varyans analizi sonuçlarına göre arazi hazırlığı ve arazi hazırlığı-kültür bakımı etkileşiminin dip çap artımına etkisi istatistiki olarak önemsiz bulunmuştur ( $\mathrm{P}>0,05$; Tablo 2$)$. Farklı arazi hazırlıkları yapılan sahalarda ortalama fidan dip çap artımı, dikim öncesi herbisit uygulanan alanda 0,87 cm olurken geleneksel arazi hazırlığı yapılan alanda ise $0,93 \mathrm{~cm}$ olarak bulunmuştur.

Kültür bakımlarının fidan dip çap artımına etkisi önemli bulunmuştur $(\mathrm{P}<0,05$; Tablo 2). Mekanik ve kimyasal ot mücadelesi işlemleri birbirleriyle benzer ve kontrole kıyasla daha yüksek çap artımı göstermiştir.

Kültür bakımı yapılan işlemlerde dip çap artımı kontrolden \%56 daha fazladır (Şekil 2).

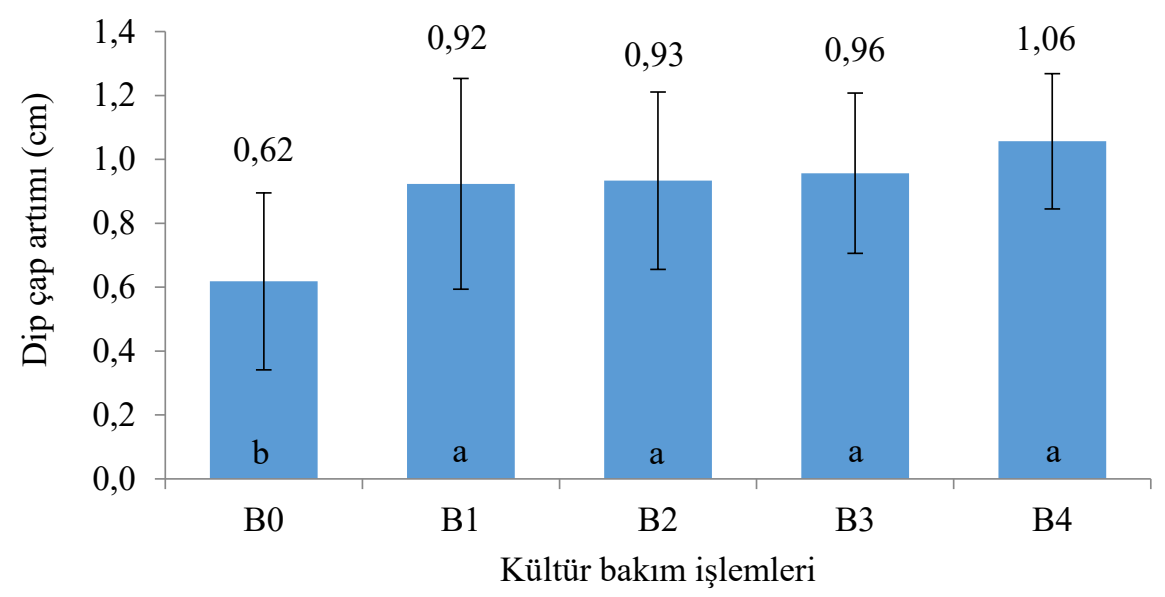

Şekil 2. Kültür bakım ișlemlerinin dip çap artımına etkisi

Figure 2. Effect of weed control treatments on the increment of root collar diameter 


\subsection{Fidan boyu}

Dikim sonrası 2012 yılı ve 2015 yılı fidan boyu Tablo 3'te verilmiştir. Fidanların 2012 y1lı ortalama boyu 84,3 cm iken 2015 yılında 178,8 cm olmuştur. Arazi hazırlığı ve arazi hazırlığ1-kültür bakımı etkileşiminin fidan boyu artımına etkisi istatistiki olarak önemsiz iken kültür bakımının etkisi önemlidir (Tablo 4). Arazi hazırlığında herbisit uygula- mas1 yapılan sahalarda, ortalama fidan boyu artımı $99 \mathrm{~cm}$ olurken geleneksel arazi hazırlığ 1 yapılan alanda ortalama $85 \mathrm{~cm}$ olarak gerçekleşmiştir. Kültür bakım işlemlerinin fidan boyu artımına etkileri karşılaştırıldığında, kültür bakımı görmeyen kontrol işlemi diğerlerinden anlamlı miktarda düşük boy artımı yapmıştır (Şekil 3). Buna göre herbisit uygulama işlemi kontrole göre $\% 69$, çapa işlemi ise \%45 daha fazla fidan boyu artımı sağlamıştır.

Tablo 3. DYD fidanların dikim sonrası 2012 ve 2015 yıllarındaki boyları (cm) Table 3. The heights of NLA seedlings (cm) in 2012 and 2015

\begin{tabular}{ccccccccccc}
\hline \multirow{2}{*}{$\begin{array}{c}\text { Ölçüm } \\
\text { Zaman1 }\end{array}$} & \multicolumn{4}{c}{ Arazi hazırlı̆̆ında herbisit uygulama } & \multicolumn{5}{c}{ Geleneksel arazi hazırlığ } \\
\cline { 2 - 11 } & B0 & B1 & B2 & B3 & B4 & B0 & B1 & B2 & B3 & B4 \\
\hline 2012 y1l1 & 86,7 & 94,8 & 85,4 & 82,1 & 88,2 & 77,1 & 84,7 & 81,2 & 80,6 & 82,4 \\
2015 y1l1 & 175,8 & 199,0 & 163,5 & 206,7 & 211,0 & 128,3 & 176,2 & 174,0 & 174,3 & 179,6 \\
\hline
\end{tabular}

Tablo 4. Arazi hazırlığ 1 ve kültür bakım ișlemlerinin fidan boy artımına ilișkin varyans analizi sonuçları (AH: Arazi hazırlığı, KB: Kültür bakımı)

Table 4. ANOVA results for the effects of site preparation and weed control treatments on the height increment

\begin{tabular}{lccccc}
\hline Varyasyon kaynağ1 & $\begin{array}{c}\text { Serbestlik } \\
\text { derecesi }\end{array}$ & $\begin{array}{c}\text { Kareler } \\
\text { toplam1 }\end{array}$ & $\begin{array}{c}\text { Kareler } \\
\text { ortalamas1 }\end{array}$ & Hesaplanan F & $\begin{array}{c}\text { Alfa tipi hata } \\
\text { ihtimali }\end{array}$ \\
\hline Arazi hazırlığ1 & 1 & 1398,648 & 1398,648 & $4,461 \mathrm{~ns}$ & 0,1018 \\
Hata-1 & 4 & 1254,217 & 313,554 & & \\
Kültür bakımı & 4 & 7855,556 & 1963,889 & $6,289 * *$ & 0,0034 \\
AH*KB & 4 & 1228,633 & 307,158 & $0,984 \mathrm{~ns}$ & 0,4454 \\
Hata-2 & 16 & 4996,127 & 312,258 & & \\
Genel & 29 & 16733,181 & 577,006 & & \\
\hline
\end{tabular}

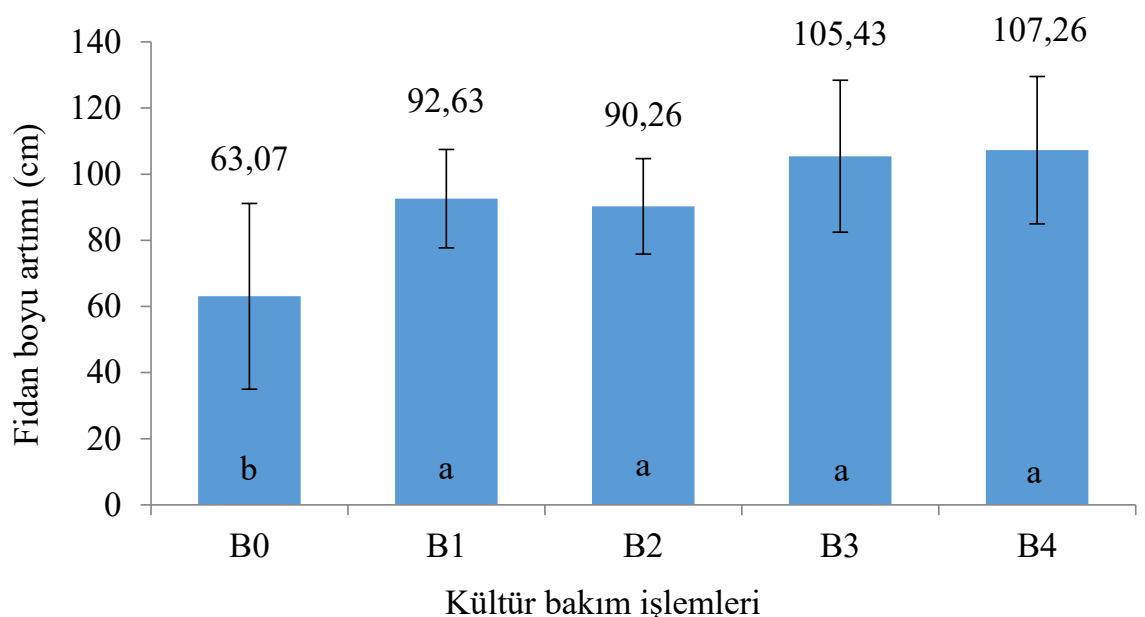

Şekil 3. Farklı kültür bakımlarının fidan boy artımına etkisi

Figure 3. Effect of different weed control treatments on the height increment

\section{4. $\mathrm{B} / \mathrm{C}$ oranı}

Deneme başlangıcında işlem parsellerine dikilen fidanların $\mathrm{B} / \mathrm{C}$ oranı bakımından farklı olup olmadığını görmek maksadıyla ANOVA testi uygulanmış ve dikim sonrası 2012 yılı B/Ç oranı değerlerinin istatistiki anlamda benzer $(88,4)$ olduğu görülmüştür. Ayrıca arazi hazırlığı, kültür bakımı 
ve arazi hazırlığı x kültür bakımı etkileşiminin 2015 yıllındaki B/Ç oranına etkisi de istatistiki olarak önemsizdir (Tablo 5). Fidanların 2015 yılı B/Ç oranı 97,6 olup üç yılda \%10 oranında artış göstermiştir.

\subsection{Fidan hacmi}

Dikim sonrası 2012 yılı fidan hacimleri işlemlere göre benzer olup ortalama fidan hacmi 32,67 $\mathrm{cm}^{3}$ 'tür. Fidanların 2015 yılı hacimleri de işlemlere göre benzer ve ortalama $261,20 \mathrm{~cm}^{3}$ olarak belir-

Tablo 5. Arazi hazırlığı ve kültür bakım işlemlerinin fidan B/Ç oranına etkisine ilişkin varyans analizi sonuçları

Table 5. ANOVA results for the effects of site preparation and weed control treatments on H/D ratios

\begin{tabular}{|c|c|c|c|c|c|c|}
\hline & Varyasyon kaynağ 1 & $\begin{array}{c}\text { Serbestlik } \\
\text { derecesi }\end{array}$ & $\begin{array}{l}\text { Kareler } \\
\text { toplam1 }\end{array}$ & $\begin{array}{c}\text { Kareler } \\
\text { ortalamas1 }\end{array}$ & Hesaplanan F & $\begin{array}{l}\text { Alfa tipi hata } \\
\text { ihtimali }\end{array}$ \\
\hline \multirow{6}{*}{ 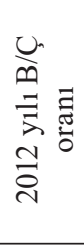 } & Saha hazırlı̆̆ $1(\mathrm{SH})$ & 1 & 923,707 & 923,707 & 6,794 & 0,121 \\
\hline & Hata-1 & 4 & 1603,345 & 100,209 & & \\
\hline & Kültür bakımı (KB) & 4 & 749,462 & 187,365 & 1,870 & 0,165 \\
\hline & $\mathrm{SH}^{*} \mathrm{~KB}$ & 4 & 133,066 & 33,266 & 0,332 & 0,852 \\
\hline & Hata-2 & 16 & 1603,345 & 100,209 & & \\
\hline & Genel & 29 & & & & \\
\hline \multirow{6}{*}{ 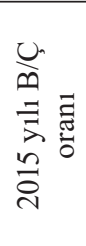 } & Saha hazırlı̆g 1 (SH) & 1 & 475,18 & 475,177 & 3,762 & 0,192 \\
\hline & Hata-1 & 4 & 1405,09 & 87,818 & & \\
\hline & Kültür bakımı (KB) & 4 & 618,01 & 154,502 & 1,759 & 0,186 \\
\hline & $\mathrm{SH}^{*} \mathrm{~KB}$ & 4 & 298,25 & 74,563 & 0,849 & 0,515 \\
\hline & Hata-2 & 16 & 1405,09 & 87,818 & & \\
\hline & Genel & 29 & 4201,62 & 879,88 & & \\
\hline
\end{tabular}

Tablo 6. Arazi hazırlığı ve kültür bakımının fidan hacmine etkisine ilişkin varyans analizi sonuçları Table 6. ANOVA results for the effects of site preparation and weed control treatments on seedling volume

\begin{tabular}{lccrcr}
\hline \multicolumn{1}{c}{ Varyasyon Kaynağ1 } & $\begin{array}{c}\text { Serbestlik } \\
\text { derecesi }\end{array}$ & Kareler toplamı & $\begin{array}{c}\text { Kareler } \\
\text { ortalamas1 }\end{array}$ & Hesaplanan F $\begin{array}{c}\text { Alfa tipi } \\
\text { hata ihtimali }\end{array}$ \\
\hline Saha hazırlığ 1 (SH) & 1 & 27823,383 & 27823,383 & 1,538 & 0,3407 \\
Hata-1 & 4 & 145228,621 & 9076,789 & & $0,0498^{*}$ \\
Kültür bakımı (KB) & 4 & 109292,343 & 27323,086 & 3,010 & 0,8739 \\
SH*KB & 4 & 10878,602 & 2719,650 & 000 \\
Hata-2 & 16 & 145228,621 & 9076,790 & & \\
Genel & 29 & & & & \\
\hline
\end{tabular}

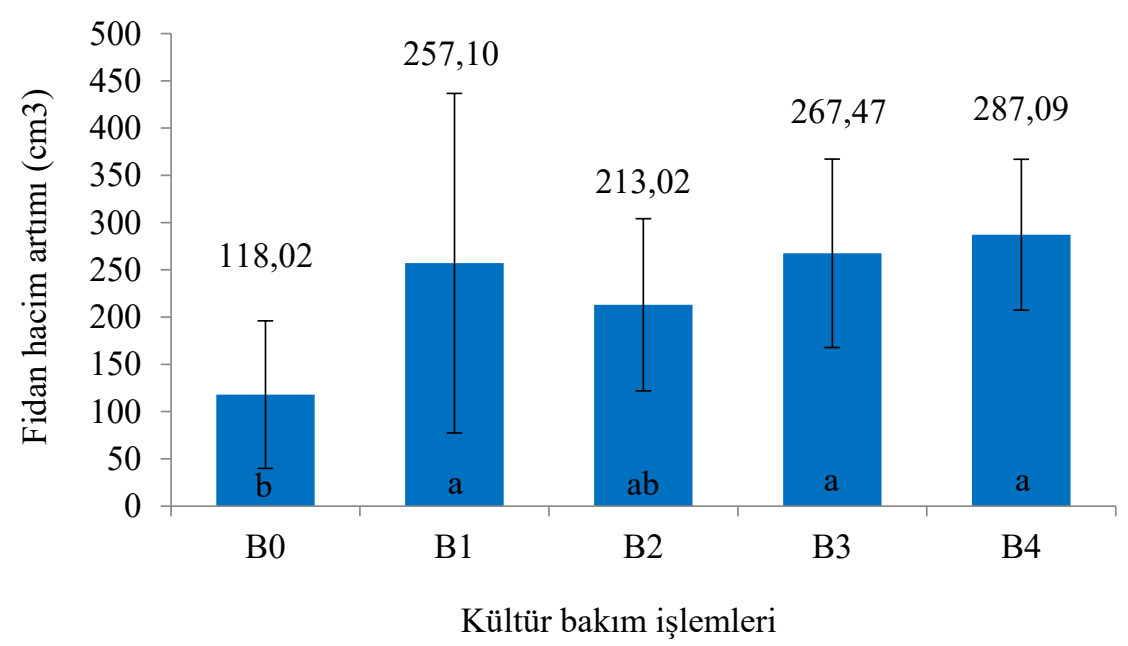

Şekil 4. Farklı kültür bakımlarının fidan hacim artımına etkisi

Figure 4. Effect of different weed control treatments on the increment of seedling volume 
lenmiştir. Ancak, arazi hazırlığı ve arazi hazırl1ğ1-kültür bakımı etkileşiminin fidan hacim art1mına etkisi istatistiki olarak önemsiz iken kültür bakımının etkisi önemli bulunmuştur (Tablo 6). İki yıl çapa uygulaması hariç diğer kültür bakımları kontrole göre \%53 daha fazla hacim artımı sağlamışlardır (Şekil 4).

\section{Tartışma ve Sonuçlar}

Arazi hazırlığı ve kültür bakım işlemlerinin fidan yaşama yüzdelerine etkisi olmamıştır. Fidan yaşama yüzdesi toprak işlemesi yapılmayan alanda $\% 88$, yapılan alanda ise $\% 92$ düzeyinde bulunmuştur. Benzer şekilde Çiçek ve ark. (2010) yaptıkları bir çalışmada, DYD fidanlarının dikimden 3 yıl sonraya kadar $\% 98$ ve üzerinde yaşama yüzdesine sahip olduğunu belirtmektedirler.

Arazi hazırlığı dip çap, boy, hacim artımı ve B/Ç oranını etkilememiştir. Benzer olarak, Hızal ve ark. (2010) farklı toprak işlemesinin toprakların bazı fiziksel özellikleri ile Sahil çamının (Pinus pinaster Aiton.) büyüme-gelişmesi üzerine etkilerini araştırdıkları çalışmada, çeşitli toprak işleme yöntemleriyle işlenmiş toprakların, ağaçların çap, boy ve hacim artımları üzerinde önemli bir etki yapmadığını belirlemişlerdir. Ayrıca, dişbudak (Fraxinus pennsylvanica Marsh.) ağaçlandırma sahasında toprak işlemesi yapılan ve yapılmayan alanda iki farklı herbisit uygulanmasını konu alan bir çalışmada, iki herbisitin (Glyphosate ve Sulfometuron) dişbudağın çap ve boy artımında etkili olduğu, ancak toprak işlemesinin herhangi bir etki yapmadığı belirlenmiştir (Groninger ve ark., 2004; Groninger ve Babassana, 2002). Diğer yandan, arazi hazırlığ1 ve diri örtü kontrolünün Juglans nigra, Fraxinus americana, Tilia americana ve Populus deltoides türlerinin yaşama yüzdesi ve boy büyümesinde etkili olduğu belirlenmiştir (Alten, 1976).

Bu çalışmada da 2012 ve 2015 yılları B/Ç değeri 100'ün altındadır. Benzer şekilde bir yaşındaki DYD fidanlarında bu oranın 52-63 arasında değiştiği belirtilmektedir (Çiçek ve ark., 2011). B/Ç oranı ağaç türüne, ekim/dikim sıklığına ve 1şık miktarına göre değişebilmektedir. Yapılan bir çalışmada $\mathrm{B} / \mathrm{C}$ oranının türe göre değiştiği ifade edilmekte ve dişbudakta 184, elmada 178 ve kayında 156 olarak ölçülmüş olup 1şık miktarı arttıkça bu oranın azaldığ 1 belirtilmektedir (Petritan ve ark., 2009). Ayr1ca gölge ağaçlarının ışık ağaçlarından daha düşük $\mathrm{B} / \mathrm{C}$ oranına sahip olduğu belirtilmektedir (Beaudet ve Messier, 1998).

Görüldüğü üzere, arazi hazırlığının fidan gelişimine etkisi yetişme ortamı özelliklerine, tür fark- 1ılığına göre değişebilmektedir. Bu çalışmamızda geleneksel arazi hazırlığı yapılan alanda odunsu diri örtünün uzaklaştırılmasıyla fidanların kök gelişimleri için nispeten daha iyi bir ortam hazırlanmıştır. Ancak geleneksel arazi hazırlığı esnasında nispeten üst toprağın taşınması (Ayık ve Yılmaz, 1992) ve vejetatif olarak çoğalma istidadında olan bitkilerin (böğürtlen, Smilax, vb.) tahrik edilmesiyle söz konusu olabilir. Bu nedenle, geleneksel arazi hazırlığı uygulanan alanda dikilen fidanların kök gelişimi için hazırlanmış olan uygun ortam koşullarının, fidanların büyüme ve gelişmesinde yapacağı olumlu etkinin, üst toprak verimliliğindeki azalma ve sarılıcı bitki oranlarındaki artma ile etkisiz hâle geldiği düşünülmektedir.

Dikim sonrası uygulanan kültür bakım işlemleri kontrole göre dip çap artımını $\% 55$, boy atımını $\% 57$ ve hacim artımını da \%53 oranında artırmıştır. Ancak kültür bakımlarının etkileri hususunda fark bulunmamıştır. Benzer birçok çalışmada da kültür bakımlarının fidan büyümesini artırdığ 1 belirtilmektedir. Çiçek ve ark. (2010) çapalama ve diskaro çekimi ile yapılan kültür bakımının DYD fidanlarında \%31 daha fazla çap ve boy gelişimi sağladığı bildirilmektedir. Ayberk ve ark. (1983), ot alınmış parsellerdeki boy ve çap gelişimi ile tutma başarısının diğer parsellerden daha yüksek olduğunu belirlemişlerdir. Farklı 16 herbisit, toprak işleme ve kontrolden oluşan bir çalışmada Azafenidin herbisit uygulaması en iyi boy büyümesini sağlayan işlem olmuştur (Woeste ve ark., 2005). Ata (1982) yapay ve doğal gençleştirme alanlarında otsu ve odunsu diri örtü karışımlarında 2,4-D, TCA, G1yphosate kullanılmasını önermektedir. İstatistiki açıdan fark olmasa da, herbisit uygulanan sahalarda fidan boyu ortalama $2 \mathrm{~m}$, çapa uygulanan parsellerde ise ortalama $1,78 \mathrm{~m}$ boya ulaşmıştır. Denemenin uygulandı̆̆ sahanın taban arazide yer alması ve yoğun diri örtü istilası altında bulunması gibi nedenlerle fidan boy gelişiminin çap gelişiminden daha önemli olduğu düşünülebilir. $\mathrm{Bu}$ tür sahalarda ağaçlandırmanın ilk iki yılında diri örtünün 1,5-2,0 m boya ulaştığ dir (Çiçek ve ark., 2007a). Dişbudağın diri örtü ve özellikle ot rekabetine karşı çok hassas olduğu belirtilmektedir (Kerr ve Evans,1993). Toprak nemi ve besin maddesi rekabetinin yanı sıra diri örtünün 1ş1k mücadelesi ve verdiği fiziksel zarar, fidanların yaşamasını ve gelişmesini olumsuz etkilemektedir (Evans, 1984; Kerr ve Evans, 1993; Kerr, 1995). Deneme alanının bulunduğu yerde arazi haziran ayı başına, bazen de haziran ayı ortasına kadar suyla doygun olduğu için çapalama yapılamamaktadır. Nitekim bu hususta Çiçek ve ark. (2007b), toprak tav hâlinin su basmasına ve mevsimsel yağ1ş durumuna bağlı olarak haziran ayı başı, ortası 
veya sonuna denk gelebildiğini belirtmektedirler. $\mathrm{Bu}$ tür ortamlarda herbisit kullanımı çapaya göre 1,0-1,5 ay gibi daha önceden uygulanma imkânı vermekte ve dolayısıyla fidanların aktif büyüme döneminde ortamdan daha fazla faydalanması söz konusu olabilmektedir.

Arazi hazırlığı kapsamında köklerin sökülmediği ve toprak işlemesinin yapılmadığı alanda uygulanan sistemik etkili herbisitin dişbudak, böğürtlen (Rubus L.) ve dikenucu (Smilax L.) gibi türlerin sürgünleri üzerinde etkili olmadığı görülmüştür. Köklerin söküldüğü alanda ise dişbudak kütük sürgünlerine pek rastlanmazken yüksek vejetatif üreme yeteneğinde olan dikenucu ve bögürtlen gibi türlerin daha yoğun gelişme gösterdiği gözlemlenmiştir. Bu nedenle farklı saha hazırlığ 1 yapılan her iki alanda da dikimi müteakip, sürgün kontrolünün yapılması önem arz etmektedir. Arazi hazırlığ1 ve kültür bakımlarında daha pratik ve ucuz olması nedeniyle herbisit kullanımı önerilebilir. Sürgün kontrolünde sistemik etkili total herbisit kullanılarak arazi hazırlanması da öneriler arasındadır. Herbisitin çevreye zarar verip vermediğinin (Kolpin ve Linhart, 1998) yanı sıra DYD kütük sürgünü, dikenucu ve böğürtlen gibi herbisit uygulamasına direnç gösteren bitkilerin uzaklaştırılmasında kullanılabilecek herbisit çeşidi, dozu ve uygulama zamanı hakkında daha fazla araştırmaya ihtiyaç duyulmaktadır.

\section{Teșekkür}

$\mathrm{Bu}$ araştırma Kavak ve Hızlı Gelişen Orman Ağaçları Araştırma Enstitüsü Müdürlüğü tarafından yürütülen "Arazi hazırlığı ve kültür bakım yöntemlerinin dar yapraklı dişbudağın (Fraxinus angustifolia ssp. oxcycarpa Vahl.) ağaçlandırma başarısına etkileri” isimli İZT-384 (1319)/ 20132016 numaralı proje kapsamında yürütülmüştür. Araştırmanın deneme alanlarının kurulmasında destek sağlayan başta dönemin Sakarya Orman Bölge Müdürü Hasan TÜRKYILMAZ olmak üzere, Hendek Orman İşletme Müdürü Mustafa ARPACI, Süleymaniye Orman İşletme şefleri Didem TOZAN ve Ahmet BALABAN'a teşekkür ederiz. Ayrıca arazi çalışmalarında emeği geçen Enstitümüzün tüm yardımcı personeline teşekkür ederiz.

\section{Kaynaklar}

Alten, F.W.von. 1976. Effects of site preparation and post-planting weed control on the survival and height growth of planted hardwood seedlings. Report, Great Lakes Forest Research Centre, Canada, No. O-X-248, pp. 15 pp.

Ata, C. 1982. Ormanda Diri Örtü İle Savaşım, K.T.Ü. Orman Fakültesi Dergisi, Say1:1, Cilt:5, Sayfa 64-88,
Trabzon.

Ayberk, S., Tolay, U., Bul, M., Zoralioğlu, T. 1983. Maki Sahalarda Arazi Hazırlığı Metotlarının P. Pinaster Aiton'un Gelişimi Üzerine Etkilerinin Araştırılması. Teknik Bülten No: 19, İzmit.

Ayık, C. ve Yılmaz, H., 1992. Diri örtü temizliği ve toprak işleme ekipmanlarının ağaçlandırma sahalarının toprakları üzerindeki etkileri, Kavak ve Hızlı Gelişen Yabanc1 Tür Orman Ağaçları Araştırma Enstitüsü Teknik Bülten No. 155, İzmit

Beaudet M, Messier C (1998) Growth and morphological responses of yellow birch, sugar maple, and beech seedlings growing under a natural light gradient. Can J Res 28:1007-1015. doi:10.1139/ cjfr-28-7-1007.

Birler, A.S., 2010.Türkiye'de Kavak Yetiştirme. Çeşitli Yayınlar Serisi No: 22, Araştırma Müdürlüğü Yayın No:262, ISSN: 1300-395X Çevre ve Orman Bakanlığ1, Kavak ve Hızlı Gelişen Orman Ağaçları Araştırma Müdürlüğü, İzmit.

Cicek, E., Y1lmaz, M. 2002. The Importance of Fraxinus angustifolia Subsp. oxyacarpa as a Fast Growing Tree for Turkey, pp. 192-202. In Proceedings. IUFRO Meeting. Management of Fast Growing Plantations. $11^{\text {th }}-13^{\text {th }}$ September 2002, İzmit, Turkey, 192-200.

Çiçek, E. 2004. Subasar Ormanların Özellikleri ve Türkiye'nin Subasar Ormanlar1, İstanbul Üniversitesi Orman Fakültesi Dergisi, 54 (2), 107-114.

Cicek, E., Tilki, F., Kulaç, S., Yılmaz, M., Yılmaz, F. 2007a. Survival and growth of three hardwood species (Fraxinus angustifolia, Ulmus laevis and U. minor) on a bottomland site with heavy clay soil. J. Plant Sci., 2, 233-237.

Cicek, E., Cicek, N., Bilir, N. 2007b. Effects of seedbed density on one-year-old Fraxinus angustifolia seedling characteristics and out planting performance. New Forests, 33(1), 81-91.

Cicek, E., Yilmaz, F., Tilki, F., Cicek, N. 2010. Effects of spacing and post-planting treatments on survival and growth of Fraxinus angustifolia seedlings. Journal of Environmental Biology, 31(4): 515.

Cicek, E., Cicek, N. ve Tilki F. 2011. Four-year field performance of Fraxinus angustifolia Vahl. and Ulmus laevis Pall. seedlings grown at different nursery seedbed densities.. Res. J. Forest., 5: 89-98.

Davis, P.H. 1987. Flora of Turkey and the East Aegean Islands. Vol. 7, Edinburgh.

Evans, J. 1984. Silviculture of Broadleaved Woodland. HMSO, London.

Fraxigen, 2005. Ash species in Europa: biological characteristics and practical guidelines for sustainable use, a summary of findings from the fraxigen. Project EU Project EVK-CT-00108, Oxford Forestry Institute, University of Oxford, UK. 
Groninger, J.W., Baer, S.G., Babassana, D.A., Allen, D.H. 2004. Planted green ash (Fraxinus pennsylvanica Marsh.) and herbaceous vegetation responses to initial competition control during the first 3 years of afforestation. Forest Ecology and Management 189:161-170.

Groninger, J.W., Babassana, D.A. 2002. Accelerating planted green ash establishment on an abandoned soybean field. In: Outcalt KW, editor. Proceedings of the eleventh biennial southern silvicultural research conference. Asheville (NC): USDA Forest Service, Southern Research Station. General Technical Report SRS-48. p 270-272.

Hızal, A., Zoralioğlu, T., Zengin, M. 2010. Çeşitli Toprak İşleme Yöntemleriyle İşlenmiş Toprakların Bazı Fiziksel Özelliklerinde Zamanla Meydana Gelen Değişimler ile Bunların Pinus pinaster Aiton Ağaçlandırmalarının Büyümesine Etkileri. Kavak ve Hızlı Gelişen Orman Ağaçları Araştırma Müdürlüğü, Müdürlük Yayın No: 260, Çeşitli Yayınlar Serisi No: 21, ISSN $1300-$ 3933. İzmit.

Kalıpsız, A 1984. Dendrometri. İ.Ü. Orman Fakültesi Yayınları, No: 3194/354, İstanbul, 407 s.

Kerr, G. 1995. Silviculture of Ash In Southern England. Forestry, Vol. 68 (1), 63-71.

Kerr, G., Evans, J. 1993. Growing Broadleaves For Timber. Forestry Commission, Handbook 9, ISBN 0-11710314-4, London.
Kolpin, D., Thurman, E. ve Linhart, S.M. 1998. The environmental occurrence of herbicides: The importance of degradates in ground water, Environ. Contam. Toxicol., 35: 385-390

Mayer, H., Aksoy, H. 1998. Türkiye Ormanları (Çev: H. Aksoy, G. Özalp). Batı Karadeniz Ormancılık Araştırma Enstitüsü Müdürlüğü, Muhtelif Yayınlar No: 1, ISSN: 975-7829-56-0, Bolu.

Petrițan, A. M., von Lüpke, B., Petrițan, I. C. 2009. “Influence of Light Availability on Growth, Leaf Morphology and Plant Architecture of Beech (Fagus Sylvatica L.), Maple (Acer Pseudoplatanus L.) and Ash (Fraxinus Excelsior L.) Saplings," European Journal of Forest Research, 128 (1), 61-74.

Pliura, A., 1999. Fraxinus spp. conservation strategy. In: Noble Harwood Network. Report of the 3rd Meeting, 1316 June 1999, Sagadi, Estonia. Edited by Turok, J. et al., International Plant Genetic Resources Institute, Rome, pp 8-20

Woeste, K.E., Seiferr, J.R., Selig, M.F. 2005. Evaluation of four herbicides and tillage for weed control on third year growth of tree seedlings. Weed Science, 53:331-336.

Yaltırık, F. 1978: Türkiye'deki Doğal Oleaceae Taksonlarının Sistematik Revizyonu. İ.Ü. Orman Fakültesi Yayın No: 2404/250, İstanbul. 